\title{
Study of Stannous-Cerium Oxide Nanocomposites as Nanofilm, Nanodot and Nanorod
}

\author{
Narender Budhiraja ${ }^{1, \star}$, Ashwani Sharma ${ }^{1}$, Sanjay Kumar ${ }^{1}$, Anupreet Kaur ${ }^{2}$, \\ N. V. Unikrishnan ${ }^{3}$ \\ ${ }^{1}$ Department of Physics, Maharshi Dayanand University, Rohtak - 124001, Haryana, India \\ ${ }^{2}$ Department of Chemistry, Punjabi University, Patiala - 147002, Punjab, India \\ ${ }^{3}$ School of Pure \& Applied Physics, Mahatma Gandhi University, Kottayam, Kerala, India \\ *E-mail address: narenderarora1988@gmail.com
}

\begin{abstract}
In the present paper, main emphasis is given to synthesize the Stannous-Cerium oxide nanocomposites in nanofilms, nanodots and nanorods by Chemical bath method, Chemical drop method and Chemical rolling Method. These nanocomposite materials are synthesized on a glass substrate at $100{ }^{\circ} \mathrm{C}$ temperature. Crystallography investigation of these materials is done by $\mathrm{X}$-ray diffraction (XRD) which reveals that average grain size is $58.9 \mathrm{~nm}$ and $62.3 \mathrm{~nm}$ for nanofilms and nanodots on glass substrate respectively whereas XRD diffraction for nanorod on glass substrate reveals that material is amorphous in nature.
\end{abstract}

Keywords: Nanofilms; Nanowires; Nanoparticles; Crystallography; Topography

\section{INTRODUCTION}

Cerium oxide films have high transparency in the visible and near IR region. It absorbs UV radiations highly efficiently. Cerium is far more abundant in the upper crust, $64 \mathrm{ppm}$, than any other rare earth elements. Cerium oxide is an excellent semiconducting material with a wide band gap. Cerium oxide has a high dielectric constant. It is also viewed as a prospective material for future microelectronic applications. $\mathrm{CeO}_{2}$ can replace silicon dioxide in electronic appliances. Cerium oxide is used significantly by the glass industry as an efficient polishing agent for most glass compositions and also to prevent the colorization of glass [1-4]. Among other oxide materials, studies of stannous oxide thin films have attained significance because of their increasing use in photovoltaic devices. The dominant use of stannous oxide is as a precursor in manufacturing of other, typically divalent, tin compounds or salts. Tin (II) Oxide (Stannous Oxide) have typical applications in pigments, electronic ceramics, capacitors, special refractory's, conductive coatings, chemicals and lens polishing $[5-11]$. 
The study of nanocomposites of stannous-cerium oxide is done for the first time. This rapidly expanding field is generating many exciting new materials with novel properties. Experimental work has generally shown that virtually all types and classes of nanocomposite materials lead to new and improved properties, when compared to their macrocomposite counterparts. Therefore, nanocomposites promise new applications in many fields such as mechanically-reinforced lightweight components, non-linear optics, battery cathodes and ionics, nanowires, sensors and other systems.

\section{EXPERIMENTAL DETAIL}

\section{1. Material}

Stannous chloride and cerium chloride are used for the synthesis of desired nanocomposites. Stannous chloride of analytical grade (M.W. 225.63) is purchased from Ranbaxy and Cerium chloride of analytical grade $(\mathrm{MW}=372.58)$ is purchased from Himedia. For the preparation of mixture solution, deionized water was used.

\section{2. Method}

2. 2. 1. Chemical Bath Deposition Technique:-

The substrate (glass slide) is immersed in the precursor of coating material at a constant speed. The thin layer deposits itself on the substrate while it is drawn upward. The speed determines the thickness of the coating material i.e. faster withdrawal gives thicker coating material. After withdrawing the substrate from precursor, it is kept in oven at $60{ }^{\circ} \mathrm{C}$. The solvent evaporates from the liquid, forming the thin layer.

\section{2. 2. Chemical Drop Method}

The Same way is followed for preparing a precursor of coating material. Then a drop is made to fall on a ultrasonicated glass substrate with the help of dropper. After that, substrate is kept in oven at $60{ }^{\circ} \mathrm{C}$, so that the solvent evaporates from the liquid, forming the nanodot.

\section{2. 3. Chemical Rolling Method}

In this method, an ultrasonicated glass rod is immersed in a precursor of coating material. The immersed rod is rolled over a substrate i.e. glass slide. For drying process, substrate is kept in oven at $60^{\circ} \mathrm{C}$.

\section{RESULTS}

\section{1. X-Ray Diffraction}

XRD pattern of Stannous Cerium Oxide nanofilm on glass substrate is shown in Fig. 1(a). The particle size of as prepared samples were found using Scherrer formula

$$
\mathrm{D}=0.9 \lambda / \beta \cos \theta
$$

where $d=$ average crystalline size, $\beta$ is full width at half maxima (FWHM), $\theta$ is the Bragg angle, $\lambda$ is the wavelength of $\mathrm{Cu} \mathrm{K}_{\alpha}$ in radians. The particle size comes out to be $58.9 \mathrm{~nm}$. 
Counts

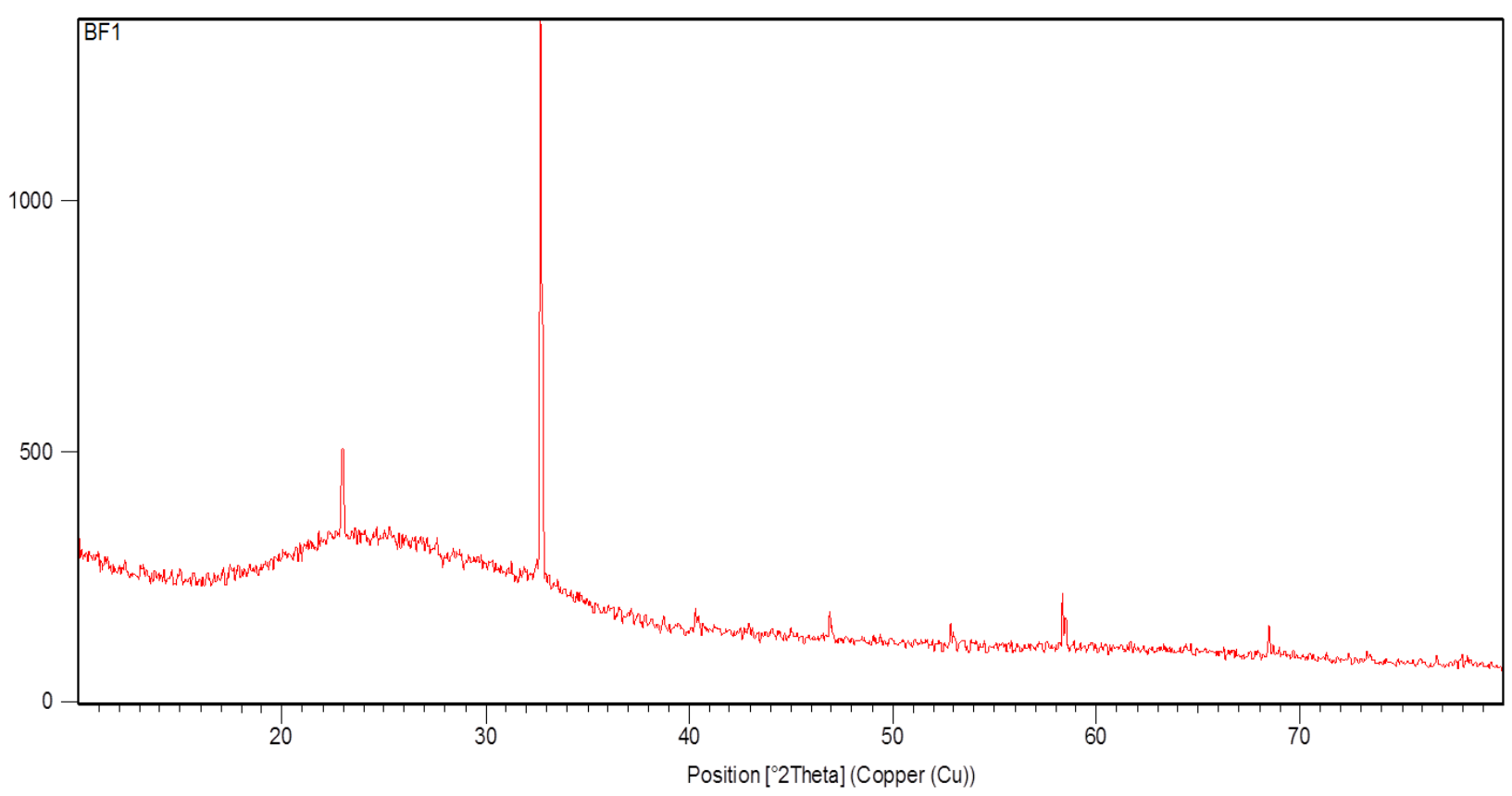

Fig. 1(a). XRD pattern of Stannous Cerium Oxide nanofilm on glass substrate.

Counts

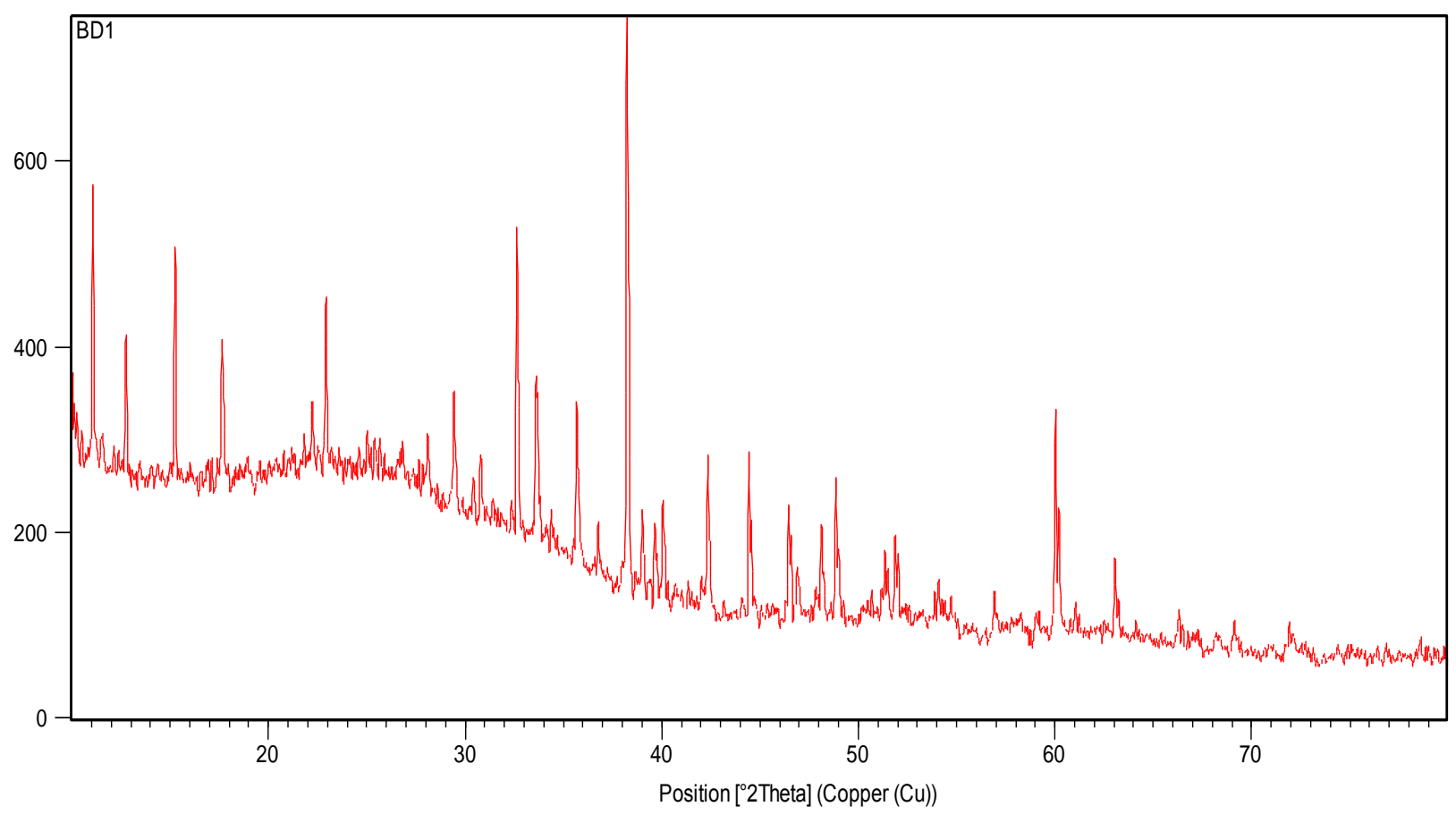

Fig. 1(b). XRD pattern of Stannous - Cerium Oxide nanodot on glass substrate. 
Counts

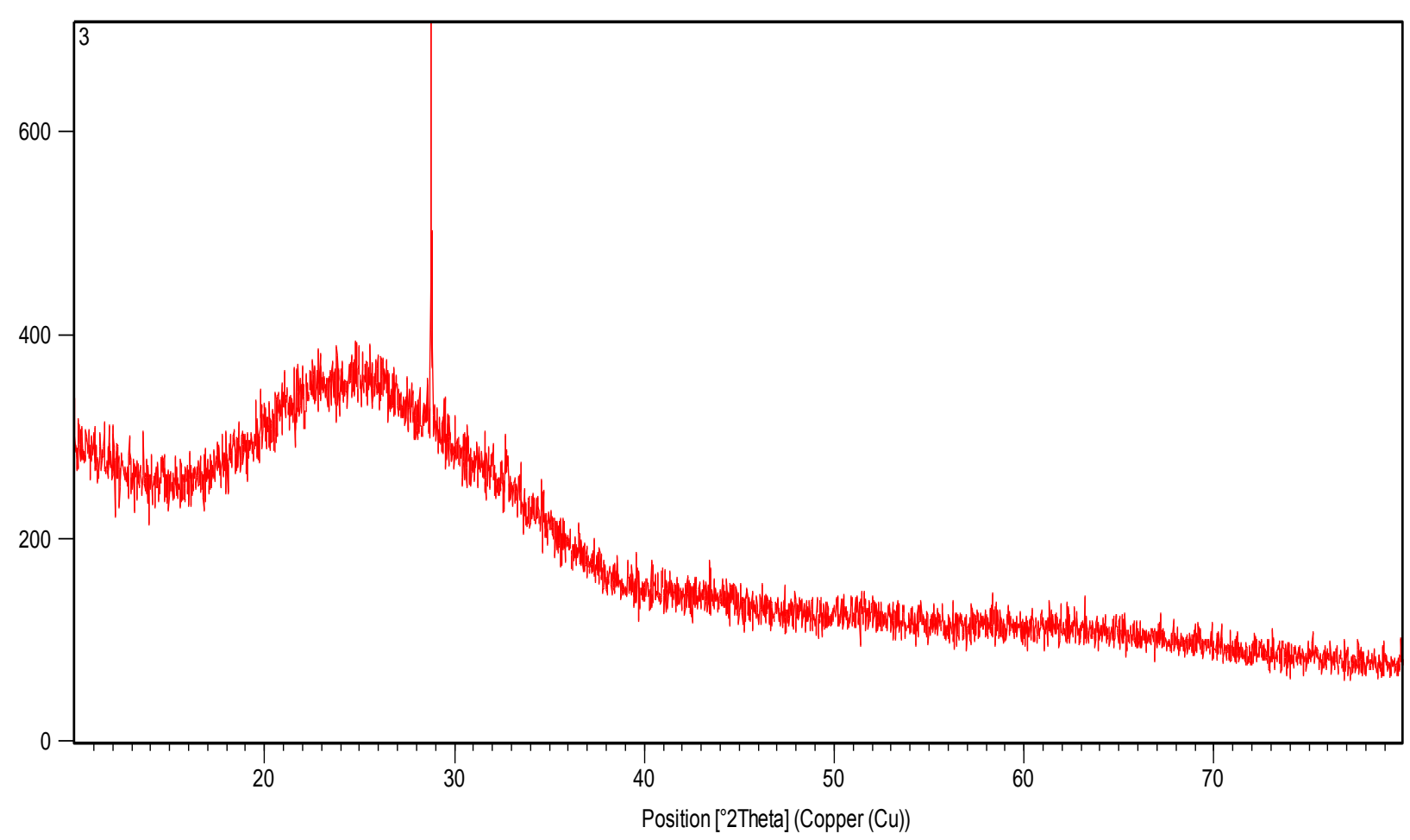

Fig 1(c). XRD pattern of Stannous-Cerium Oxide nanorod on glass substrate.

XRD pattern of Stannous - Cerium Oxide nanodot on glass substrate is shown in Fig 1(b). The crystalline size comes out to be $62.3 \mathrm{~nm}$. XRD pattern of Stannous - Cerium Oxide nanorod on glass substrate is shown in Fig. 1(c). It is amorphous in nature [12-17].

\section{2. Visible spectroscopy}

A convenient method of characterizing the nanomaterial is UV/VIS absorption spectroscopy. Nanofilm, Nanodot and Nanorod of Stannous - Cerium Oxide on glass substrate have absorption edge towards shorter wavelength.

This blue shift is taken as indication of presence of nanocrystals [18-20]. VIS spectra of nanofilm is shown in Fig. 2(a). In the visible region, transmission increases linearly. VIS spectra of nanodot is shown in Fig. 2(b).

In the visible region, transmission increases and there is small peak at $450 \mathrm{~nm}$ and then there is a sharp peak at $500 \mathrm{~nm}$ and then transmission decreases up to $560 \mathrm{~nm}$ and then it sharply rises again.

VIS spectra of nanorod is shown in Fig. 2(c). In the visible region, transmission increases linearly just like VIS spectra of nanofilm. 


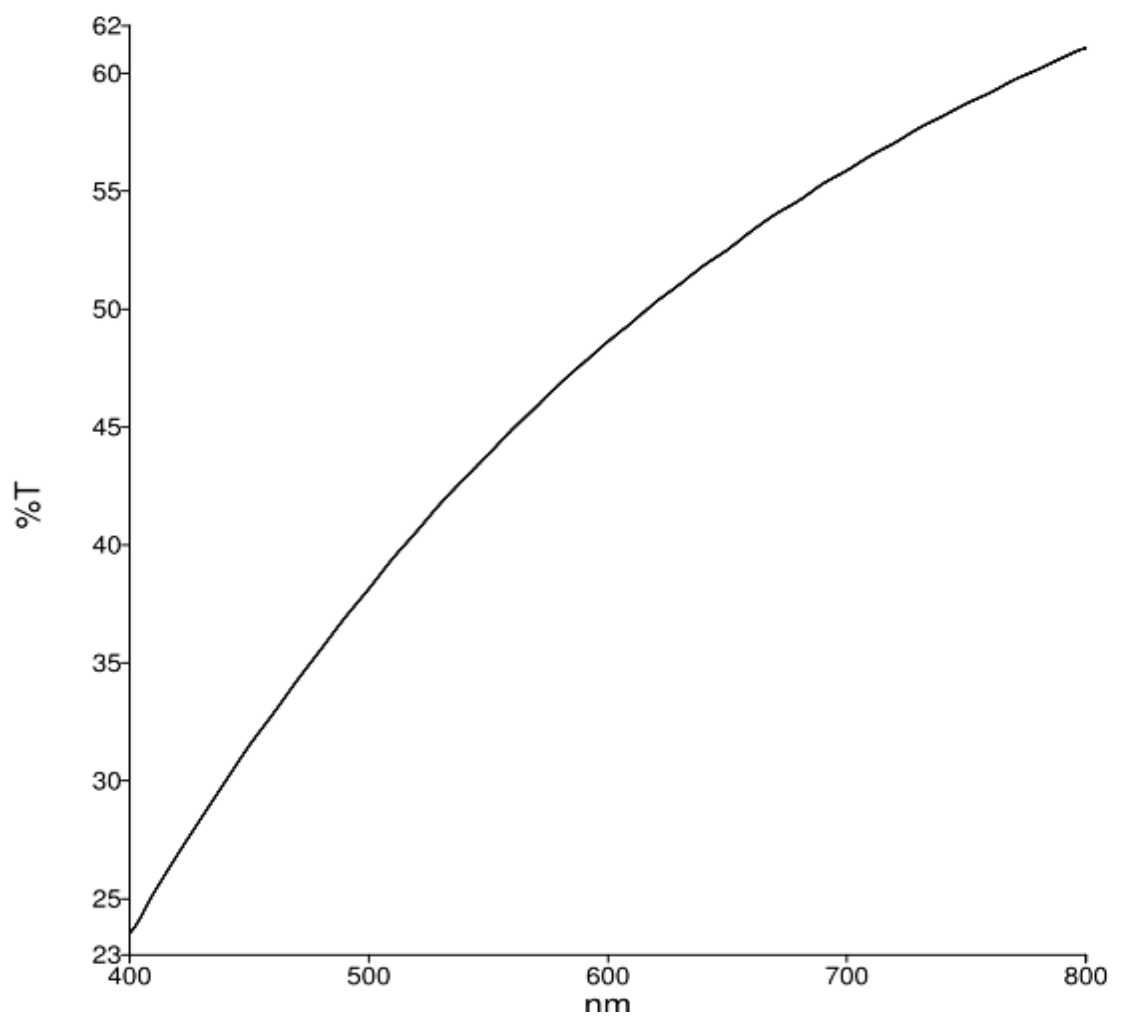

Fig. 2(a). VIS spectra of Stannous Cerium Oxide nanofilm on glass substrate.

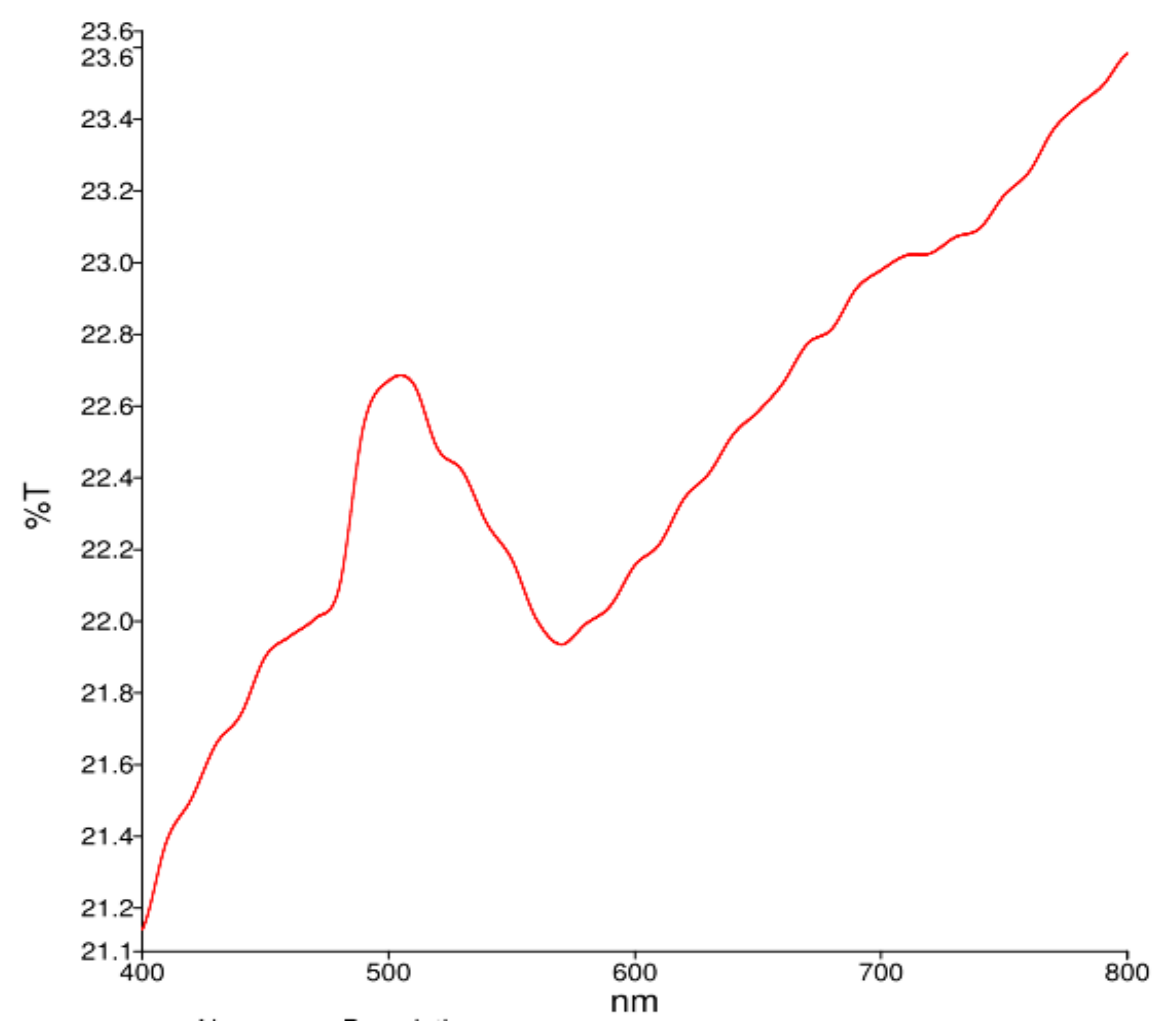

Fig. 2(b). VIS spectra of Stannous Cerium Oxide nanodot on glass substrate. 


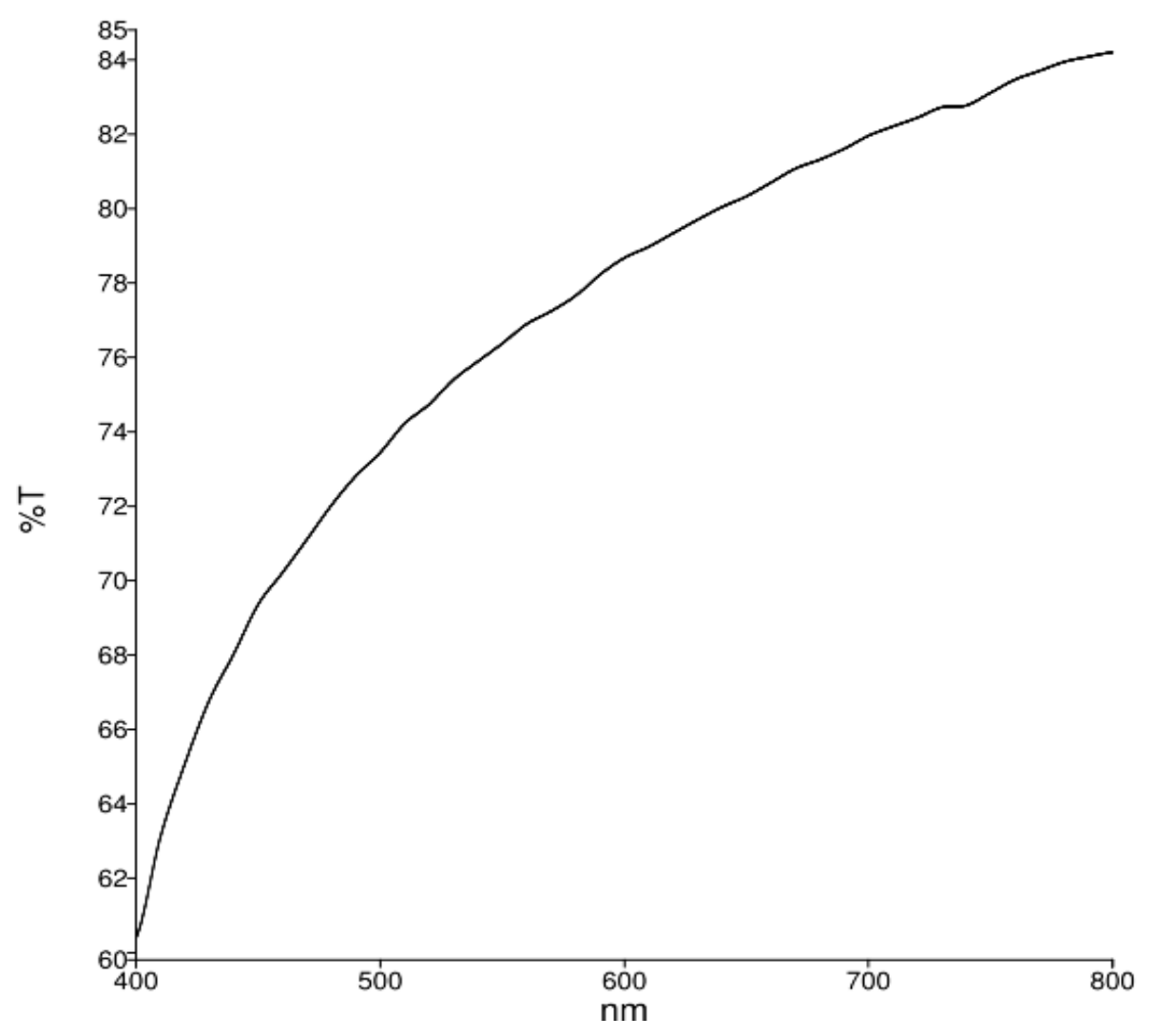

Fig. 2(c). VIS spectra of Stannous Cerium Oxide Nanorod on glass substrate.

\section{3. Scanning electron microscope}

SEM image of Stannous-Cerium oxide nanofilm on glass substrate is shown in Fig. 3 and Fig. 4.

SEM image of Stannous-Cerium oxide nanofilm on glass substrate have crystallites having uniform grain size.

SEM image of Stannous-Cerium oxide nanodots on glass substrate is shown in Fig. 5 and Fig. 6. The surface of the film is homogeneous and uniformly spread. It is devoid of cracks and pores.

SEM image of Stannous-Cerium oxide nanorods on glass substrate is shown in Fig. 7 and Fig. 8.

It is shown that the surface of Stannous-Cerium Oxide nanorod on glass substrate prepared by sol gel method is smoother and clear [21-23]. 


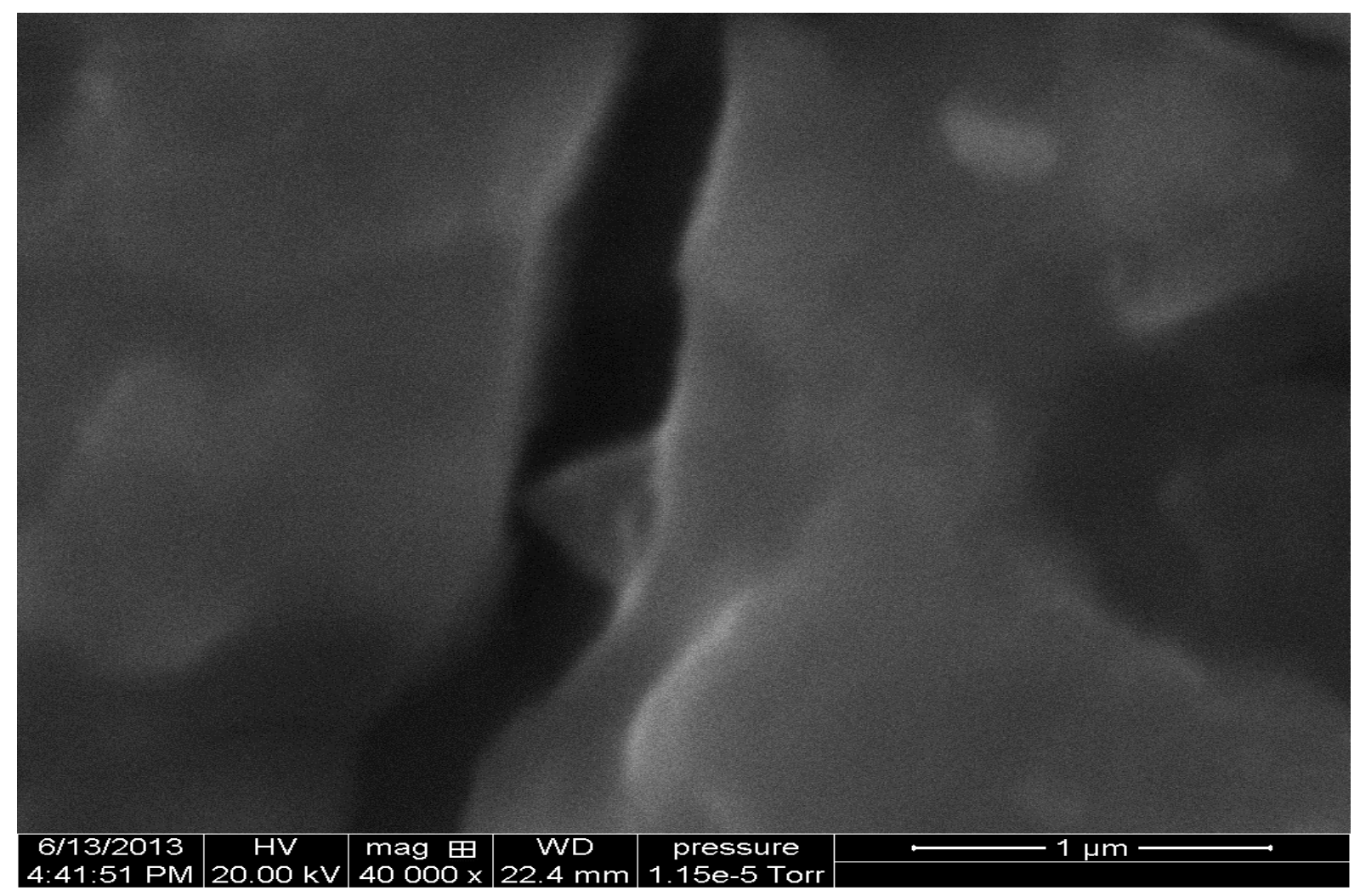

Fig. 3. SEM of synthesized Stannous-Cerium oxide nanofilm at magnification 40,000x.

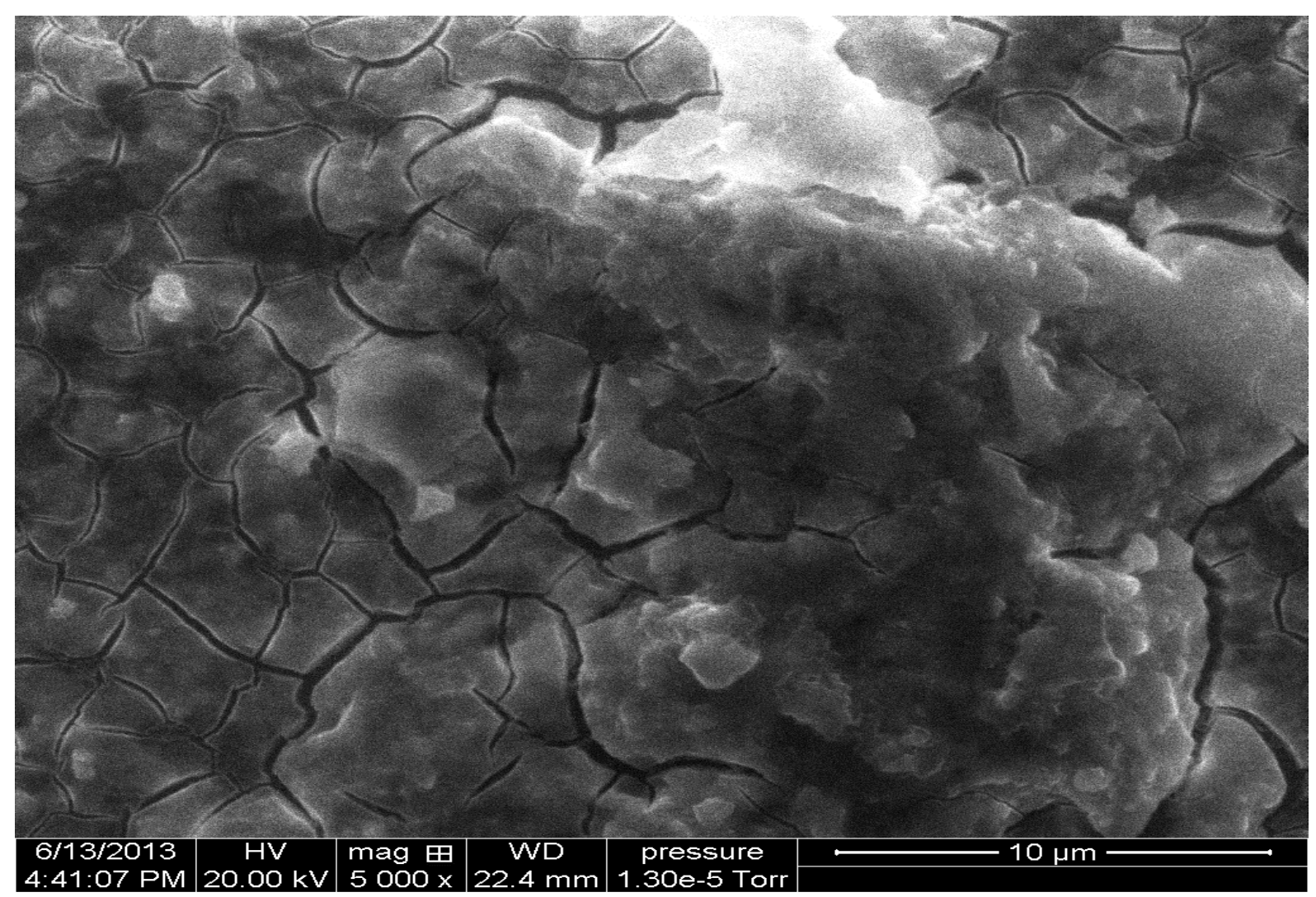

Fig. 4. SEM of synthesized Stannous-Cerium oxide nanofilm at magnification 5000x. 


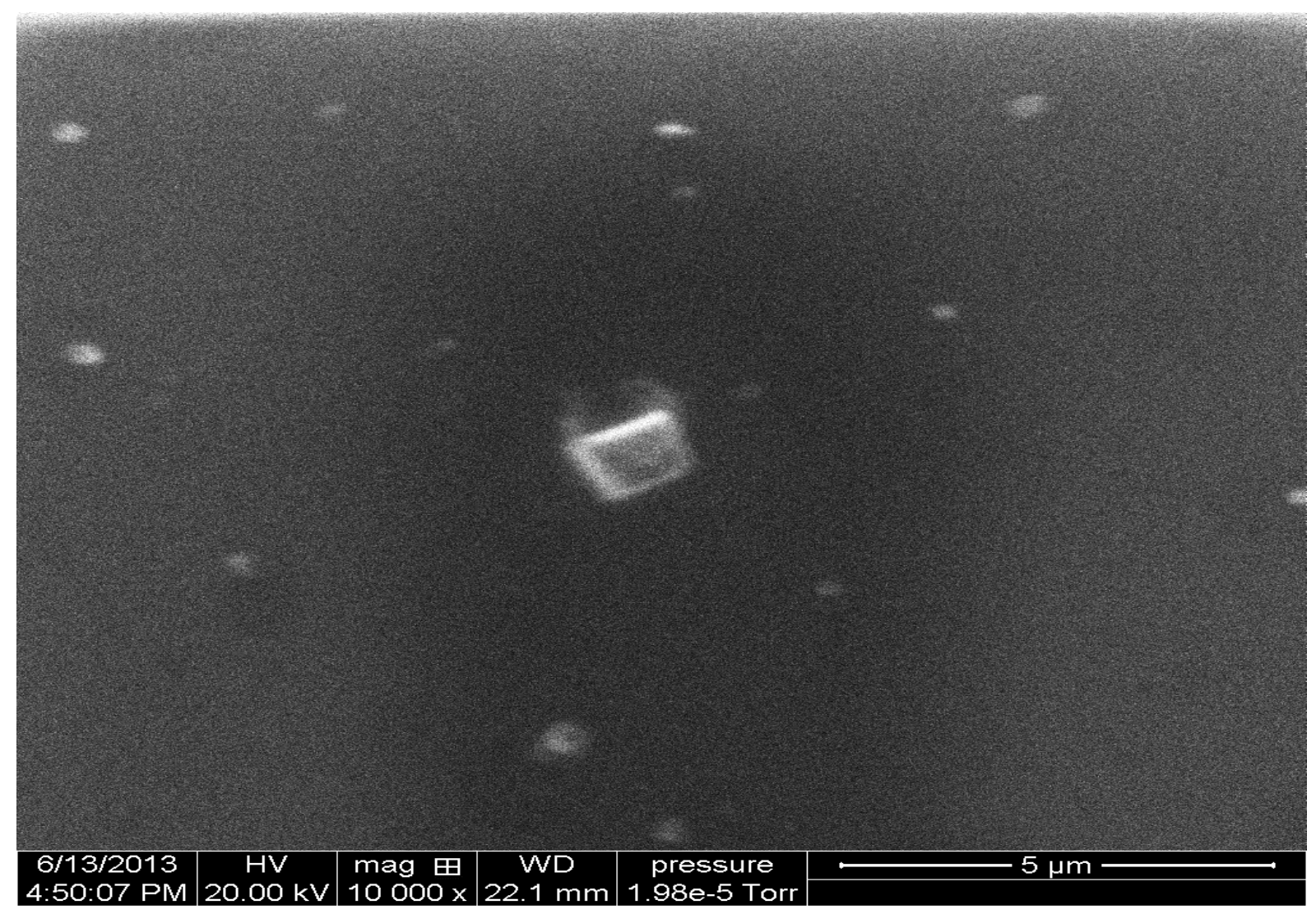

Fig. 5. SEM of synthesized Stannous-Cerium oxide nanodot at magnification 10,000x.

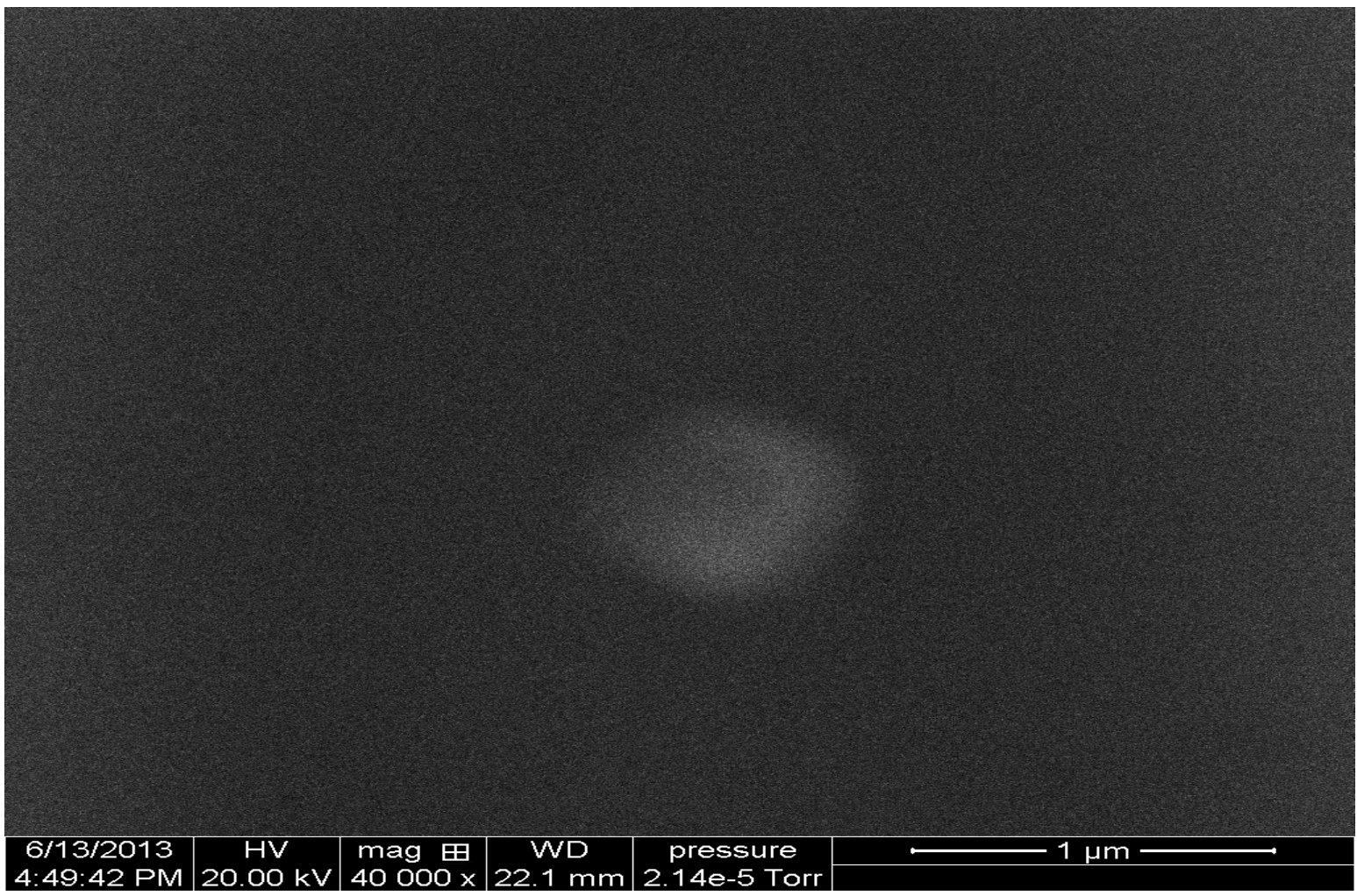

Fig. 6. SEM of synthesized Stannous-Cerium oxide nanodot at magnification 40,000x. 


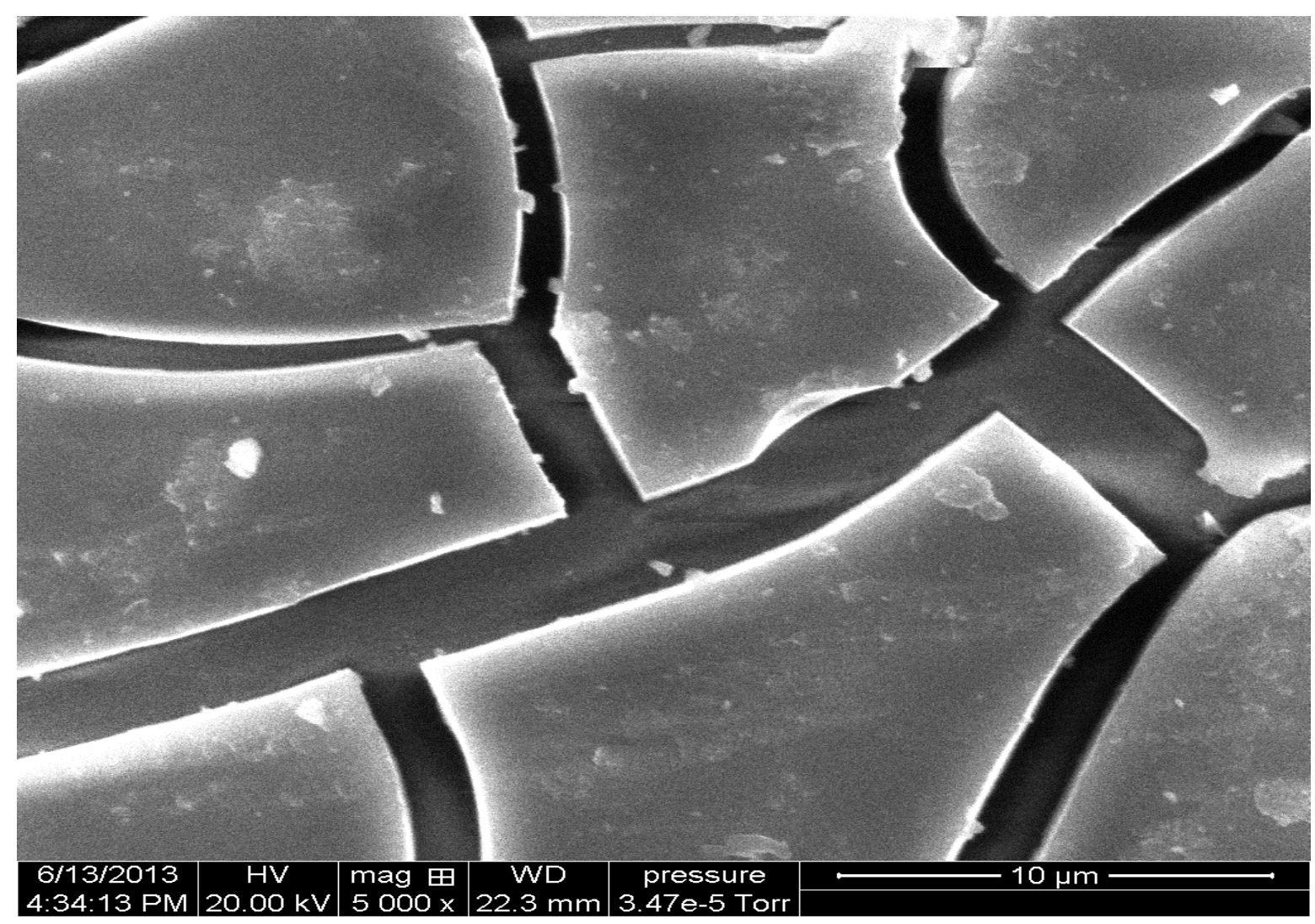

Fig. 7. SEM of synthesized Stannous-Cerium oxide nanorod at magnification 5000x.

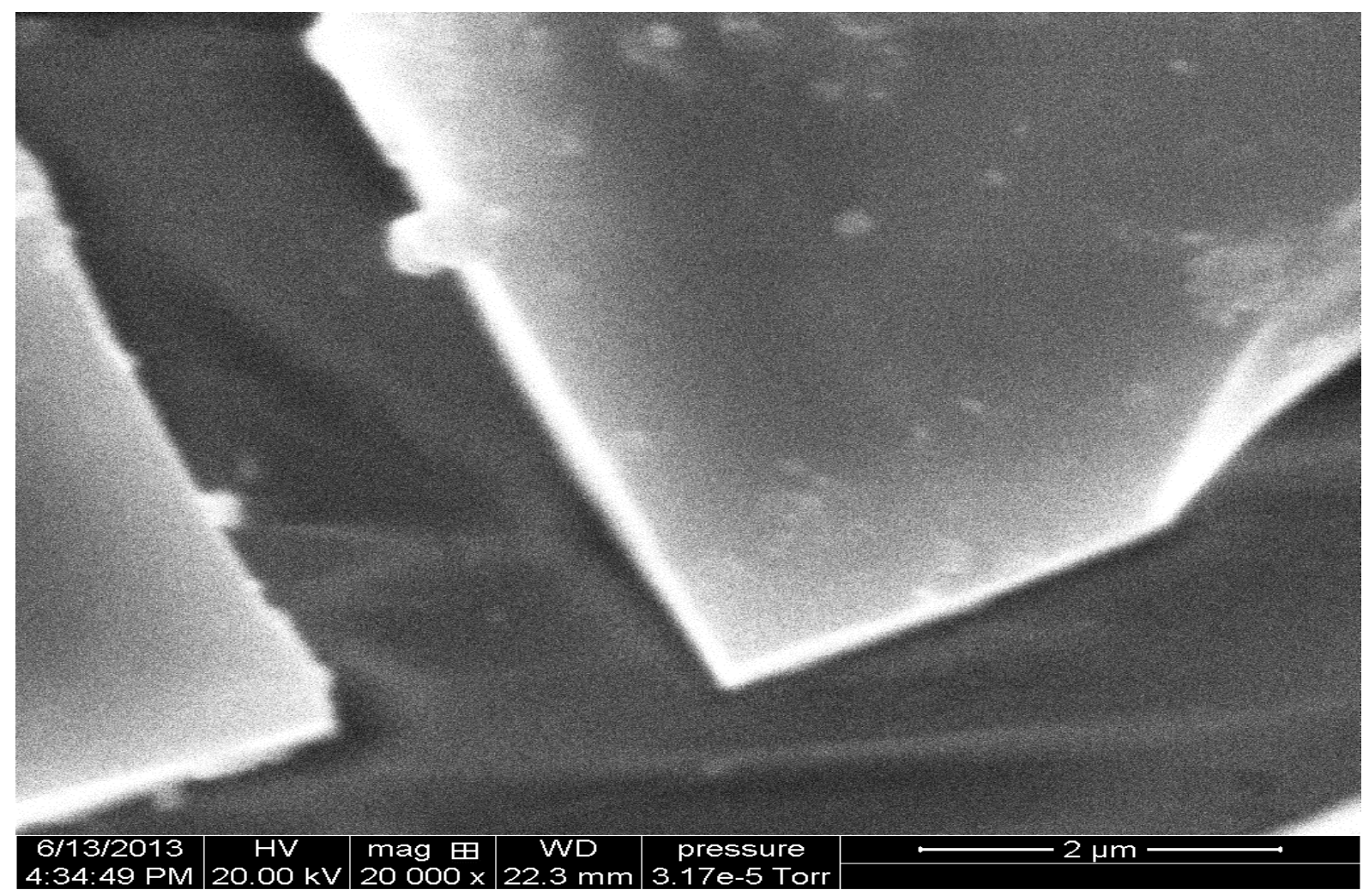

Fig. 8. SEM of synthesized Stannous-Cerium oxide nanorod at magnification 20,000x. 


\section{4. Ellipsometry data}

The thickness of the film is calculated using Ellipsometer. The thickness of the nanofilm on glass substrate comes out to be $243 \mathrm{~nm}$ (Error: $\pm 2.5 \mathrm{~nm}$ ). The thickness of the nanodot on glass substrate comes out to be $3080 \mathrm{~nm}$ (Error: $\pm 5.3 \mathrm{~nm}$ ). The thickness of the nanorod on glass substrate comes out to be $883.4 \mathrm{~nm}$ (Error: $\pm 3.7 \mathrm{~nm}$ )

\section{CONCLUSIONS}

Thin films of Stannous-cerium oxide nanomaterials is prepared on glass substrate by Chemical Bath Method. The structural and optical properties of the prepared StannousCerium oxide thin film on glass substrate have been confirmed using SEM, XRD and VIS spectroscopy. The thickness of the Stannous-Cerium oxide nanodot on glass substrate comes out to be $3080 \mathrm{~nm}$ (Error: $\pm 5.3 \mathrm{~nm}$ ), of nanofilm on glass substrate comes out to be $243 \mathrm{~nm}$ (Error: $\pm 2.5 \mathrm{~nm}$ ) and of nanorod on glass substrate is equal to $883.4 \mathrm{~nm}$ (Error: $\pm 3.7 \mathrm{~nm}$ ). It is observed that the average crystalline size of Stannous-Cerium oxide nanofilm on substrate comes out to be $58.9 \mathrm{~nm}$ and Stannous-Cerium oxide nanodots on glass substrate comes out to be $62.3 \mathrm{~nm}$. Stannous-Cerium oxide nanorods on glass substrate is amorphous in nature. All samples of nanofilm, nanodot and nanorod shows sharp absorption edges in the visible region and these absorption edges slightly shifted to shorter wavelengths (blue shift).

\section{Acknowledgement}

Author is thankful to UGC for providing the financial support for carrying out research work. Author is thankful to Physics Dept of H.P. University, Shimla for SEM characterization and SAIF of P.U. Chandigarh for XRD and UV-VIS characterstics. Author is thankful to School of Pure \& Applied Physics, Mahatma Gandhi University, Kottayam, Kerala for carrying out thickness of thin films.

\section{References}

[1] C. G. Granqvist, Handbook of inorganic electrochromic materials, 1995.

[2] T. Nakazawa, T. Inoue, M. Satoh, Y. Yamamoto, J. Appl. Phys. 34 (1995) 548.

[3] T. J. Ahrens, Global Earth Physics, A Handbook of Physical Constants. American Geophysical Union, Washington, D.C., 1995.

[4] A. Trovarelli, Catalysis by Ceria and Related Materials. 1st ed.; Imperial College Press: London, p. 508, 2002.

[5] G. W. Hunter, C. C. Liu, D. B. Makel, in: M.G.Hak (Ed), The MEMS Hand Book, CRC Press pp. 1-22, 2002.

[6] A. Goetzberger, C. Helbling, Sol. Energy Mater and solar cells 62 (2000) 1.

[7] R. S. Niranjan, I. S. Mulla., Mater. Eng. B (2003) 103.

[8] O. K. Varghase, L. K. Malhotra, Sensor \& Actuators 53 (1998) 19.

[9] N. S. Baik, G. Sakai, N. Miura, N. Tamajoe, Sensor \& Actuators, 63 (2000) 74. 
[10] E. Comini, G. Faglia, G. Sberveglieri, Z. Pon, Z. L. Wang., Appl. Physics Lett. 81(10) (2002) 1869.

[11] V. S. Vaishnav, P. D. Patel, N. G. Patel, Thin solid films 490 (2005) 94.

[12] Zang H., Lacefield W. R., Biomaterials 21 (2000) 23.

[13] R. Viswanatha, T. G. Venkatesh, C. C. Vidyasagar, Y. Arthoba Nayaka, Archives of Applied Science Research 4(1) (2012) 480-486.

[14] Suresh R. Kulkarni, Archives of Physics Research 3(2) (2012) 116-122.

[15] S. B. Kondawar, S. D. Bompilwar, V. S. Khati, S. R. Thakre, V. A. Tabhane, D. K. Burghate, Archives of Applied Science Research 2(1) (2010) 247.

[16] Panneerselvaml, S. Ponarulselvam, K. Murugan, Archives of Applied Science Research 3(6) (2011) 208.

[17] Xu W. L., Zheng M. J., Wu S., Shen W. Z., Appl. Phys. Lett. 85 (2004) 4364.

[18] X. R. Ye, C. Daraio, C. Wang, J. B. Talbot, Jin Journal of Nanoscience and Nanotechnology 6 (2006) 852.

[19] Shankar S. S., A. Ahmed, B. Akkamwar, M. Sastry, A. Rai, A. Singh, Nature 3 (2004) 482.

[20] Jain D. H, D. Kumar, S. Kachhwaha, S. L. Kothari, J. of Nanomaterials and Biostructures 4 (2009) 557.

[21] Choi J., Luo Y., Wehrspohn R. B., Hillebrand R., Schilling J., Gösele U, J. Appl. Phys. 94 (2003) 4757.

[22] Ding G. Q., Shen W. Z., Zheng M. J., Fan D. H., Appl. Phys. Lett. 88 (2000) 103-106.

[23] Wu G. S., Xie T., Yuan X. Y., Li Y., Yang L., Xiao Y. H., Zhang L. D., Solid State Commun 134 (2006) 485. 